\title{
Introduction: Rosalind Krauss
}

\section{Douglas Rosenberg}

In an interview with the host of Bravo Television's Actor's Studio, Dustin Hoffman recounts a dinner conversation with the great actor Sir Laurence Olivier. The dinner takes place amongst friends and family during the last days of Olivier's battle with cancer and the filming of his last film, Marathon Man. Hoffman becomes visibly emotional as he recounts the story, filling in the details of Olivier's children tenderly greeting their dying father, his wife the actress Joan Plowright and others at the table. Hoffman had wanted to hear the great Olivier's ideas about why actors act, why Olivier acted, so he asks the question, "Tell me, what's the reason we do what we do?" Hoffman recounts that Olivier got up from the table and leaned over to him, placing his face inches from Hoffman's own and after a pause, said, "You want to know why, dear boy? Look at me, look at me, look at me, look at me, look at me, look at me, look at me, look at me, look at me, look at me."

The following essays were written while contemplating the essay, "Video: The Aesthetics of Narcissism," by Rosalind Krauss. This essay was published in the influential journal October in 1976 and has resonated throughout the history of media practice since its first printing. The essay opens with this well-known passage:

It was a commonplace of criticism in the 1960s that a strict application of symmetry allowed a painter "to point to the center of the canvas" and, in so doing, to invoke the internal structure of the picture-object. Thus "pointing to the center" was made to serve as one of the many blocks in that intricately constructed arch by which the criticism of the last decade sought to connect art to ethics through the "aesthetics of acknowledgement." But what does it mean to point to the center of a t.v. screen?"

Krausse raises the specter of narcissism in a particular early video work by the artist Vito Acconci, who, in a nod to "Duchampian irony," films himself in close-up, pointing to the center of the television set upon which we see his image for a period of twenty minutes. Krausse goes on to explain that in this gesture of "self regard," Acconci uses the video monitor as a mirror. She notes that: "In that image of self-regard is configured a narcissism so endemic to works of video that I find myself wanting to generalize it as the condition of the entire genre. Yet, what would it mean to say, 'The medium of video is narcissism?"'"2

Or, perhaps we might re-phrase the question and ask: is the medium of screendance narcissism? After all, if the video monitor or the video camera is relied on in a similar way (using Krause's mirror analogy), doesn't it simply become an extension of the mirrored studio, the reification of the dancing body, albeit a more edited, better version of itself? And doesn't center-stage often become center-screen as choreographic ideas are migrated or translated to screenic space? Finally, what is worth 
discussing, as in the following pages, is the possibility that screendance may function in some cases as the material equivalent of Sir Laurence Olivier's mantra, "Look at me, look at me, look at me, look at me, look at me, look at me, look at me, look at me, look at me, look at me."

\section{References}

Krauss, Rosalind. "Video: The Aesthetics of Narcissism." October 1 (Spring 1976): 50-64.

\section{Notes}

1. Krauss, "Narcissism," 50.

2. Ibid., 50 . 